\title{
Mercado de trabalho: uma abordagem setorial por nível educacional, gênero e raça para o ano de 2008
}

\author{
Kézia de Lucas Bondezan* \\ Willian Oura Suzuki ** \\ Ricardo Luis Lopes ***
}

Resumo: O estudo referente ao mercado de trabalho é relevante para a Ciência Econômica por ser o espaço onde os indivíduos produzem bens e serviços para a sociedade e recebem a renda necessária para a garantia do seu bem estar. Sabe-se que o mercado de trabalho possui forte relação com o nível de educação do trabalhador, gênero e raça às quais pertencem. Diante deste contexto, cabe discutir: a distribuição do número de trabalhadores no Brasil; os setores com maior contratação de mão de obra e a distribuição educacional por gênero e raça destes trabalhadores. Este trabalho faz esta abordagem utilizando-se da metodologia de insumo-produto. Com dados da PNAD e matriz de insumo-produto para o ano de 2008. Para identificar os setoreschaves da economia, calculam-se os índices de Rasmussen-Hirschman e os índices GHS normalizados. Também são calculados os multiplicadores de renda e emprego, juntamente com os multiplicadores de emprego voltados para gênero e raça, visando caracterizar o mercado de trabalho brasileiro. Através dos cálculos realizados e da análise dos dados, os setores-chaves identificados foram: Refino do Petróleo, Siderurgia e Elementos Químicos, todos eles com maior multiplicador de emprego para o grupo de alto nível educacional. Verificou-se também que os setores de maior concentração de homens e mulheres apresentam baixo rendimento mensal médio, não exigindo alta qualificação. Pessoas de raça branca tendem a atuar em setores de maior rendimento e possuem maior nível educacional. Por fim, percebe-se maior rendimento mensal médio conforme aumenta o nível de instrução do indivíduo.

Palavras Chaves: insumo-produto, multiplicador de emprego e renda, setores-chaves

Abstract: The study for the labor market is relevant to Economics because it is the

\footnotetext{
* Professora Adjunta - Unespar/FECEA. kezialucas@hotmail.com

** Professor Assistente - Universidade Presbiteriana Mackenzie. w.suzuki@hotmail.com

*** Professor Adjunto - UEM. rllopes@uem.br
} 
space where people produce goods and services to society and receive the income necessary to guarantee their welfare. It is known that the labor market has a strong relationship with the level of worker education, gender and race to which they belong. In this context, it is important to discuss: the distribution of the number of workers in Brazil, the sectors with greater hiring of labor, and education distribution by race and gender of workers. The methodology used is the input-output, PNAD data and inputoutput matrix for the year 2008. To identify the key-sectors of the economy, we compute the Rasmussen-Hirschman indices and standardized GHS. Also, we calculated income multipliers and employment multipliers along with employment-oriented gender and race, in order to characterize the Brazilian labor market. Through the calculations performed and the data analysis, the key-sectors identified were: Petroleum Refining, Steel and Chemicals, all of them with higher employment multiplier for the group of high academic standards. Moreover, it was found that the sectors with the highest concentration of men and women have a low average monthly income and do not require high qualifications. White people tend to act in areas of higher income because they have greater access to education. Finally, the higher the level of education, the higher the average monthly income.

Keywords: input-output, employment and income multipliers, key-sectors

\section{Introdução}

O mercado de trabalho no Brasil é bastante diversificado e isto pode ser observado através de fatores como: distribuição dos postos de trabalhos e de rendimentos, nível de escolaridade, ocupação por gênero e raça e outras características observáveis e não observáveis.

Citando como exemplo, a Agropecuária absorve em torno de 18\% da mão-de-obra no Brasil, segundo os dados da PNAD de 2008. Do total de ocupados nesse setor, $25 \%$ não possuem instrução e 55\% não concluíram o ensino fundamental. O rendimento médio é de aproximadamente $\mathrm{R} \$ 342,00$ mensais para os que não possuem nenhum grau de instrução e de $\mathrm{R} \$ 552,00$ para os que possuem fundamental incompleto. Já as pessoas alocadas neste mesmo setor e que possuem curso superior completo, o rendimento mensal passa a ser de aproximadamente $R \$ 2.270,00$. O setor tem como característica a exigência de baixa qualificação de mão-de-obra e, assim, baixo nível de instrução. Entretanto, assim como preconizado por Mincer (1974), ao aumentar o grau de escolaridade, os rendimentos tendem a ser mais elevados.

Existem também setores mais dinâmicos na economia, ou seja, aqueles que possuem relação de compra e venda com os demais setores, caso dos Elementos Químicos, considerado setor-chave da economia por apresentar alto nível de dependência interindustrial, sendo ofertante e demandante acima da média. Por outro lado, existem outros setores que são grandes compradores, porém apresentam baixa relação de venda e vice-versa, existindo também setores considerados independentes por apresentarem baixa relação de compra e venda com os demais. 
Diversos estudos econômicos que abordam a relação de mercado de trabalho buscam caracterizar quais setores têm sido mais dinâmicos na economia, quais proporcionam maiores rendimentos, bem como buscam mostrar se o aumento da escolaridade eleva a renda do trabalhador e, em caso afirmativo, de que maneira e em que valor ocorre esta elevação.

Usando a metodologia de análise de insumo-produto e dados da Matriz de Insumo Produto e da Pesquisa Nacional por Amostra de Domicílio (2008), este estudo busca contribuir para esta discussão no sentido de identificar os chamados setores-chaves da economia, levando em consideração o nível de produção de cada setor, bem como calcular os multiplicadores de emprego e renda do Brasil, distribuídos por setor, grupo educacional, gênero e raça.

O trabalho é dividido em quatro seções além desta introdução e das considerações finais. $\mathrm{Na}$ seção dois é feita uma pequena revisão bibliográfica sobre o mercado de trabalho no Brasil. A seção três apresenta a descrição metodológica adotada no presente artigo. Em seguida, faz-se uma análise descritiva dos dados, buscando identificar a distribuição ocupacional do mercado de trabalho por setor, levando em conta os grupos educacionais, a cor e o gênero. Nessa seção é apresentada a distribuição dos rendimentos médios mensais por setor e grupo educacional. Na seção quatro, são apresentados os resultados da aplicação da metodologia de insumo-produto, identificando os setores-chaves da economia e os multiplicadores de emprego e renda. Por fim, a seção final é destinada às considerações finais.

\section{Revisão de Literatura}

A relação entre a educação e renda tem como efeito o reflexo da distribuição da educação sobre a distribuição da renda, ou seja, a desigualdade da educação. As relações entre essas duas variáveis remetem a múltiplas e complexas dimensões sociais, econômicas e culturais.

A análise da influência da escolaridade na desigualdade de rendimentos permeia toda a literatura econômica sobre o tema. No Brasil, o debate precursor entre Fishlow (1972) e Langoni (1973) colocou frente a frente aqueles que consideravam a educação - tanto a sua distribuição como a natureza dos retornos - como principal determinante da distribuição de renda brasileira e o que atribuíam papel determinante ao funcionamento do mercado de trabalho.

Após o trabalho de Langoni (1973), vários estudos se dedicaram sobre o papel da educação na determinação da desigualdade de rendimentos no Brasil. Almeida e Barros (1991), por exemplo, mostram que educação e idade explicam cerca de $51 \%$ da desigualdade de rendimentos no trabalho, sendo que a eliminação dos diferenciais salariais associados à educação por si só reduziria a desigualdade em 40\%. Isso ocorre devido à má distribuição da educação na força de trabalho e aos elevados retornos econômicos à educação existentes no Brasil.

Lam e Levinson (1990) mostram que, em 1986, a desigualdade na distribuição de rendimentos no Brasil era quatro vezes maior do que nos Estados 
Unidos e que os salários aumentaram cerca de 15\% por ano de estudo, sendo uma das maiores do mundo. Barros e Mendonça (1995) afirmaram que poucos países conseguiam atingir níveis de desigualdade educacional entre trabalhadores como os do Brasil. Os autores citam os resultados obtidos em extensa literatura dedicada a estimar a contribuição das desigualdades educacionais para a desigualdade salarial no Brasil e afirmam:

Estima-se que, se os diferenciais de salário por nível educacional fossem eliminados, tudo o mais permanecendo constante, a desigualdade salarial no Brasil declinaria de 35 a 50\%. [...] A contribuição da educação é consideravelmente maior do que a contribuição de qualquer forma de segmentação e discriminação ou demais características individuais investigadas (experiência no mercado de trabalho e na empresa). (Barros \& Mendonça, 1995, p. 347).

No Brasil há desigualdades absoluta e relativa na escolaridade da população e esse é um dos principais fatores que explicam a desigualdade na distribuição de renda, pois um ano adicional de escolaridade implica em valorização salarial elevada, o que, aliado à escassez de mão-de-obra qualificada, contribui para a concentração de renda pessoal no país. Especificamente no que se refere ao mercado de trabalho, observa-se que a heterogeneidade da escolaridade entre os trabalhadores e o valor atribuído aos anos adicionais de escolaridade representam os principais determinantes da desigualdade salarial (Barros; Henriques; Mendonça, 2002).

Segundo Barros e Mendonça (1994), um aumento de um ano na escolaridade média do brasileiro aumenta cerca de 0,35\% a taxa de crescimento da renda per capita no Brasil. O mesmo estudo aponta que o aumento de um ano de escolaridade para o trabalhador brasileiro aumenta em 20\% a renda per capita do país. Considerando que, no início dos anos 90, a renda per capita brasileira (US $\$ 5$ mil) equivaleria cerca de $1 / 3$ da renda per capita observada nos países industrializados (US\$ $15 \mathrm{mil}$ ), os autores mostram que uma elevação na educação formal da força de trabalho brasileira para níveis idênticos aos dos países industrializados tenderia a dobrar esta renda no Brasil. Como decorrência, a renda per capita brasileira passaria de $1 / 3$ para $2 / 3$ do valor correspondente nos países industrializados, sugerindo que a metade do enorme hiato de renda per capita entre o Brasil e os países industrializados origina-se no baixo nível educacional da população brasileira.

Especificamente no que se refere ao impacto da educação sobre a renda per capita e o nível de salários, Barros e Mendonça (1998) mostram que para a região metropolitana de São Paulo cada ano adicional de educação superior aumenta os salários, em média, em 16\%. ${ }^{1}$ Assim, espera-se que um trabalhador com maior nível de instrução seja mais produtivo que outro com nível inferior, portanto, a educação torna-se um elemento importante no processo de desenvolvimento econômico, especialmente com relação à melhoria de produtividade de longo

1 O impacto do aumento de um ano de escolaridade secundária sobre os salários seria de $12 \%$ e o de um aumento equivalente na escolaridade primária aproxima-se de $9 \%$. 
prazo.

Barros et al. (2002) argumentam em seu trabalho que a heterogeneidade na escolaridade é o principal fator de desigualdade salarial no Brasil. Para os autores, quanto mais heterogênea a força de trabalho maior é o retorno obtido por um ano a mais de escolaridade. Assim, cabe ao governo a adoção de políticas salariais voltadas à redução desta disparidade no Brasil e, com isso, promover uma redução desses problemas.

Essa importância da educação no processo de redução das desigualdades salariais já tinha respaldo. O trabalho de Schultz (1960) foi um dos primeiros a considerar a educação como um investimento, mostrando que a mesma cria no homem um capital que não pode ser vendido, mas promove uma produtividade de alto valor econômico. $\mathrm{O}$ aumento do capital humano é, para o autor, o argumento que justifica a expansão da renda. Assim, a literatura econômica oferece uma variedade de teorias e modelos que relacionam educação e crescimento econômico. A educação aumenta o ganho potencial do indivíduo e pode apresentar diversas externalidades positivas.

Para analisar a complexidade de como a desigualdade se relaciona com educação, Barros, Henriques e Mendonça (2002) decompõem a desigualdade salarial para o Brasil e para os Estados Unidos em dois componentes: a) desigualdade salarial entre trabalhadores com o mesmo nível de escolaridade; b) desigualdade salarial entre trabalhadores com diferentes níveis de escolaridade. Dever-se-ia esperar que, em princípio, se o excesso de desigualdade no Brasil estivesse inteiramente relacionado à educação, então o nível de desigualdade salarial entre trabalhadores com a mesma escolaridade seria bastante similar nos dois países e, em contrapartida, a desigualdade entre trabalhadores com diferentes níveis de escolaridade seria muito mais elevada no Brasil. Seus trabalhos mostram que a desigualdade entre trabalhadores com o mesmo nível educacional é apenas 7\% maior no Brasil, enquanto a desigualdade entre trabalhadores com diferentes níveis de escolaridade é $478 \%$ mais elevada que nos Estados Unidos.

Quanto à distribuição ocupacional no Brasil em termos de gênero, notase que a participação da mulher no mercado de trabalho tem crescido ao longo dos anos, principalmente após a década de 70. Soares e Izaki (2002) analisaram o perfil da mulher no mercado de trabalho e observaram que, entre 1977 e 2001, a participação feminina aumentou até atingir os 45 anos de idade e em seguida começou a diminuir. Em sua análise, os autores concluíram que, até essa idade, as mulheres já educaram seus filhos e, por isso, encontram maior disponibilidade para trabalhar. Essa realidade vem mudando abruptamente, pois a cada dia as mulheres vêm se inserindo mais cedo no mercado de trabalho. Como diferença entre mulheres da década de 70 e do século XXI, Bruschini (2007) verificou que, anteriormente, eram jovens e solteiras, enquanto que atualmente, grande parte é casada e possui filhos. $\mathrm{O}$ autor aponta ainda que, quanto menor a idade dos filhos, menor a probabilidade da mulher trabalhar e, segundo seus estudos, a participação feminina é maior entre 30 e 39 anos, representando $74 \%$ das mulheres. 
Neste contexto, é válido ainda destacar a discriminação salarial entre homens e mulheres, ou seja, mulheres com a mesma função dos homens tendem a ter salários menores. Entre os muitos trabalhos que mostram essa relação, é possível citar: Camargo e Serrano (1983), Barros, Ramos e Santos (1995), Leme e Wajnman (2000), Kassouf (1998), Ometto, Hoffman e Alves (1997) e Cavalieri e Fernandes (1998).

Camargo e Serrano (1983) utilizaram dados da Relação Anual de Informações Sociais (RAIS) de 1976 e estimaram a equação de salários para homens e mulheres na indústria, controlando pelas características: pessoais, como escolaridade e gênero; e do mercado de trabalho, como intensidade de capital e proporção de trabalhadores em cargos administrativos. Os resultados concluíram que existem discriminações salariais por gênero, porém não calcularam a magnitude dessa discriminação.

Barros, Ramos e Santos (1995) também realizam esta análise utilizando dos dados da Pesquisa Nacional por Amostra de Domicílios (PNAD) para os anos de 1981 a 1989. Os autores estimaram um diferencial acima de 50\% entre os salários masculinos e femininos no período analisado. Esse percentual era não controlado e, ao inserir controles como ocupação ou inserção no mercado trabalho, educação e experiência, a diferença chega a $90 \%$.

Em linha pouco mais otimista, Leme e Wajnman (2000) apontam que o diferencial salarial por sexo reduz de $70 \%$ para $25 \%$ entre 1977 e 1997 , concluindo que, a cada geração mais jovem, a discriminação salarial desfavorável às mulheres tende a reduzir para todas as idades. Já Kassouf (1998) mostra que os diferenciais salariais entre homens e mulheres variam conforme o segmento do mercado de trabalho no qual o indivíduo está inserido. As estimativas para 1989 mostram que ambos os setores (formal e informal) possuem discriminação salarial significativa, porém, é no informal que a diferença é mais acentuada.

Ometto, Hoffman e Alves (1997) realizaram um trabalho sobre discriminação, comparando dois estados brasileiros, Pernambuco e São Paulo, e apontam que o fator gênero feminino afeta o salário em maiores proporções em Pernambuco do que em São Paulo. Por fim, Cavalieri e Fernandes (1998) apontam que a diferença salarial entre homens e mulheres varia conforme: idade, educação, cor e região. Revelam ainda que essas diferenças são menores nas regiões metropolitanas do Sul e Sudeste, entre branco e não branco e entre educados e não educados.

Ainda neste contexto de abordagem da discriminação no mercado de trabalho, é válido considerar alguns trabalhos que tratam a questão racial no mercado de trabalho brasileiro. Soares (2000) aponta diversos aspectos sobre o menor acesso ao mercado de trabalho por parte do negro, entre eles: menor peso ao nascer; maior probabilidade de falecimento na infância; menor probabilidade de frequentar creche; maior repetência escolar; e maior taxa de abandono de estudos. Essas e outras características levam os negros à menor remuneração no mercado de trabalho e, assim, condição de vida inferior a dos brancos.

Saboia e Saboia (2006) enfocaram a existência da desigualdade entre brancos e não brancos (pretos / pardos) sob perspectiva do mercado de trabalho 
brasileiro, considerando especialmente as pessoas ocupadas com nível de escolaridade de terceiro grau. Suas conclusões também foram a de que os brancos possuem situação favorável quanto ao nível educacional no Brasil e, assim, maiores remunerações. Ao observar o número de pessoas ocupadas entre as duas categorias, a situação é de equilíbrio, entretanto, ao desagregar pelas ocupações universitárias, constata-se que a participação de pretos e pardos é bem inferior a de brancos, indicando claro sinal de desigualdade na sociedade.

\section{Metodologia}

\subsection{Dados}

Os dados para a realização deste trabalho foi coletado da Pesquisa Nacional por Amostra de Domicílios / IBGE (PNAD), com referência ao ano de 2008. As variáveis coletadas foram: número de pessoas ocupadas; número de pessoas ocupadas da raça branca e não branca; número de mulheres e homens ocupados e escolaridade das pessoas ocupadas, todas elas separadas por setor da economia. Com a finalidade de caracterizar o nível educacional dos trabalhadores, a amostra foi dividida em sete grupos, conforme detalhado abaixo:

1 - Sem Instrução;

2 - Ensino Fundamental Incompleto;

3 - Ensino Fundamental Completo;

4 - Ensino Médio Incompleto;

5 - Ensino Médio Completo;

6 - Ensino Superior Incompleto;

7 - Ensino Superior Completo.

Além da base de dados da PNAD, foi também coletada a Matriz de Insumo Produto de 42 setores (IBGE), para o ano de 2008. A compatibilização das duas bases foi feita através da agregação, finalizando com 31 setores.

\subsection{Os Cálculos}

Para avaliar os impactos diretos e indiretos que as mudanças ocorridas na demanda final apresentam sobre o nível de emprego e dos salários, faz-se a identificação dos setores-chaves da economia, ou seja, os setores que causam impactos nos demais com maior intensidade. Estes impactos foram classificados por nível de instrução e tem como objetivo analisá-los. Para isso, o método utilizado será aquele adotado por Guilhoto (2004) e possui a seguinte equação:

$$
X=I L * y
$$


Sendo:

$I L=(I-A)^{-1}$ - Matriz inversa de Leontief;

$I$ - Matriz identidade;

A - Matriz de coeficientes técnicos;

$y$ - Demanda final.

A equação (1) representa o modelo básico de Leontief e a matriz inversa (IL) permite calcular as quantidades totais necessárias (direta e indiretamente) para a produção de X para atender a demanda final y. Os cálculos destas matrizes e dos multiplicadores citados nas subseções a seguir foram realizados pelos autores mediante utilização do software Freemat 4.0. Os resultados destes multiplicadores estão localizados na seção cinco.

\subsubsection{Multiplicadores}

\subsubsection{Emprego e Renda}

Segundo Miller e Blair (2009), os multiplicadores representam a diferença entre o efeito inicial de uma mudança exógena e os efeitos totais desta mudança. Neste contexto, ainda segundo os autores, entende-se por mudanças exógenas: produção dos setores na economia, renda gerada pelas famílias, emprego e valor adicionado criado por cada setor na economia. Os efeitos são chamados totais por incluírem efeitos diretos, indiretos e induzidos.

O multiplicador de emprego (ME) representa a mudança ocorrida na economia de modo geral quando há variação de uma unidade monetária no setor de análise. Neste caso, a finalidade é verificar a quantidade de emprego gerada quando ocorre a adição de $R \$ 1$ milhão em cada setor da economia brasileira. Para calcular este efeito, são necessários: matriz inversa de Leontief (IL) e coeficiente da população ocupada por grau de instrução (cPOG). Através da equação (2) abaixo, calcula-se o cPOG:

$$
c P O G=P O G * \hat{X}^{-1}
$$

Sendo POG o pessoal ocupado por grau de instrução e $\mathrm{X}$ o valor de produção. Desta maneira, é possível calcular o multiplicador de emprego:

$$
M E=c P O G * I L
$$

Já os multiplicadores de renda (MR) indicam a quantidade de renda gerada na economia por determinado setor quando este varia em uma unidade monetária. Assim, é possível verificar os setores que apresentam maiores retornos. Analogamente, são necessários a IL e o coeficiente de renda por grau de instrução (cREMG), sendo calculado através da equação (4) abaixo: 


$$
c R E M G=R E M G * \hat{X}^{-1}
$$

Em que REMG representa a remuneração da população por setor por nível de instrução. Desta maneira, por meio do coeficiente de renda, é possível obter o multiplicador de renda:

$$
M R=c R E M G * I L
$$

\subsubsection{Gênero e Raça}

De maneira análoga aos multiplicadores de emprego e de renda, é possível também calcular os multiplicadores de gênero (MG) e de raça (MRACA). $\mathrm{O}$ procedimento adotado é idêntico aos citados anteriormente, isto é, cálculo dos coeficientes de gênero e de raça e, assim, a obtenção dos multiplicadores.

O coeficiente de gênero (cGEN) é obtido por meio da equação (6):

$$
c G E N=G E N * \hat{X}^{-1}
$$

Assim, MG é obtido da seguinte maneira:

$$
M G=c G E N * I L
$$

Utilizando o mesmo método, calcula-se o coeficiente de raça (cRACA):

$$
c R A C A=R A C A * \hat{X}^{-1}
$$

Através de (9), é possível calcular MRACA:

$$
M R A C A=c R A C A * I L
$$

Sendo GEN a população ocupada distribuída nos 31 setores da economia por gênero e raça a mesma população, porém distribuída através da raça (branca e não branca).

Ao obter MG, é possível verificar a quantidade de empregos gerada na economia para homens e mulheres quando há injeção de $R \$ 1$ milhão no referido setor. Analogamente, por meio de MRACA, pode-se observar esta quantidade gerada para pessoas de raças branca e não branca quando ocorre esta mesma entrada de capital em cada setor da economia. 


\section{Análise de Insumo-Produto - Resultados e Discussões}

\subsection{Setores-Chaves}

Para identificar os setores-chaves da economia, é preciso calcular os índices de Rasmussen-Hirschman de ligação para frente (FL) e para trás (BL). Porém, para obtê-los, é preciso identificar a matriz inversa de Leontief, de dimensão 31x31. Os resultados estão apresentados na Tabela 1 e apontam o nível de dependência entre setores pelo lado da oferta e pelo lado da demanda:

Tabela 1: Índices de Ligações para Trás (BL) e para Frente (FL)

\begin{tabular}{|c|c|c|c|c|}
\hline & Setor & BL & FL & Setor-Chave \\
\hline 1 & Agropecuária & 0,9253 & 1,2777 & Não \\
\hline 2 & Ext. Mineral & 0,9261 & 0,7607 & Não \\
\hline 3 & Petróleo e Gás & 0,9186 & 1,3549 & Não \\
\hline 4 & Min. Não Metál. & 1,0606 & 0,7649 & Não \\
\hline 5 & Siderurgia & 1,0806 & 1,5616 & Sim \\
\hline 6 & Máq. e Equip. & 1,1116 & 0,7031 & Não \\
\hline 7 & Mat. Eletroelet. & 1,0992 & 0,8353 & Não \\
\hline 8 & Veíc. e Peças & 1,2324 & 0,8423 & Não \\
\hline 9 & Mad. e Mobil. & 1,0282 & 0,6995 & Não \\
\hline 10 & Celul.. Papel e Gráf. & 1,0453 & 0,9936 & Não \\
\hline 11 & Ind. Borracha & 1,1054 & 0,6201 & Não \\
\hline 12 & Elem. Químicos & 1,146 & 1,2565 & Sim \\
\hline 13 & Ref. Petróleo & 1,244 & 2,034 & Sim \\
\hline 14 & Farmac. / Veter. & 1,0359 & 0,5954 & Não \\
\hline 15 & Art. Plásticos & 1,1557 & 0,817 & Não \\
\hline 16 & Ind. Têxtil & 1,0461 & 0,9578 & Não \\
\hline 17 & Art. Vestuário & 1,0184 & 0,5528 & Não \\
\hline 18 & Fab. Calçados & 1,1766 & 0,6673 & Não \\
\hline 19 & Ind. Alimentos & 1,2871 & 0,9661 & Não \\
\hline 20 & Ind. Diversas & 1,0481 & 0,5762 & Não \\
\hline 21 & S.I.U.P. & 0,9199 & 1,354 & Não \\
\hline 22 & Const. Civil & 0,9469 & 0,6651 & Não \\
\hline 23 & Comércio & 0,7663 & 1,8182 & Não \\
\hline 24 & Transportes & 0,9621 & 1,5247 & Não \\
\hline 25 & Comunicações & 0,9066 & 1,2608 & Não \\
\hline 26 & Inst. Financeiras & 0,8169 & 1,4103 & Não \\
\hline 27 & Serv. Prest. Família & 0,9065 & 0,7185 & Não \\
\hline 28 & Serv. Prest. Empresa & 0,8407 & 1,4398 & Não \\
\hline 29 & Aluguel de Imóveis & 0,5973 & 0,7493 & Não \\
\hline 30 & Adm. Pública & 0,7986 & 0,6147 & Não \\
\hline 31 & Serv. Priv. Não Merc. & 0,847 & 0,6078 & Não \\
\hline
\end{tabular}

Fonte: Elaboração dos autores 
Verifica-se que, dos 31 setores analisados, 25 deles possuem forte índice de ligação para frente ou para trás, isto é, BL $>1$ ou FL > 1. Pode-se dizer que grande parte dos setores possui forte dependência pelo lado da oferta ou da demanda. Entretanto, para que o setor seja considerado chave, BL e FL devem apresentar valores acima de um e, assim, apenas três deles possuem tal denominação: Siderurgia, Elementos Químicos e Refino do Petróleo. Estes setores são dependentes por serem fortes ofertantes e demandantes. O Gráfico 1 é a reprodução da Tabela 1, melhorando a visualização destes setores-chaves;

\section{Gráfico 1: Índices de Rasmussen-Hirschman}

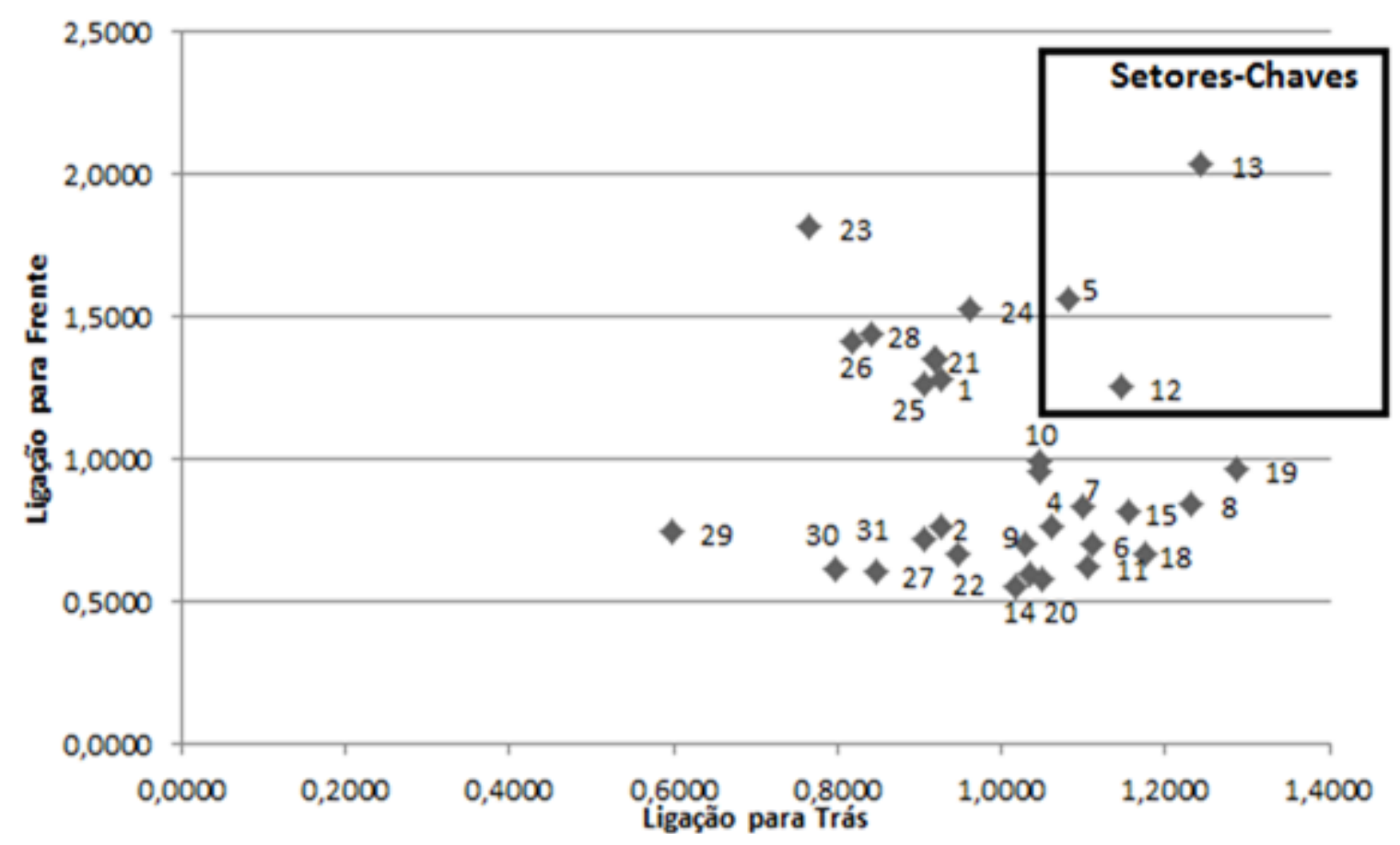

Fonte: Elaboração dos autores

\section{2 Índices GHS}

Pelo fato dos índices de Rasmussen-Hirschman não considerarem os níveis de produção de cada setor analisado, é preciso calcular os índices puros de ligação (GHS). Através das variáveis apontadas anteriormente, é possível encontrar os índices puros de ligação para trás, para frente e o total. Porém, para analisar comparativamente, é preciso normalizar estes índices GHS, cujos resultados se encontram na Tabela 2 , com os índices normalizados para trás, para frente e o total. 
Tabela 2: Índices Puros de Ligação para Trás (PBLN), para Frente (PFLN) e Total (PTN) Normalizados

\begin{tabular}{|c|c|c|c|c|}
\hline & Setor & BL & FL & Setor-Chave \\
\hline 1 & Agropecuária & 0,9253 & 1,2777 & Não \\
\hline 2 & Ext. Mineral & 0,9261 & 0,7607 & Não \\
\hline 3 & Petróleo e Gás & 0,9186 & 1,3549 & Não \\
\hline 4 & Min. Não Metál. & 1,0606 & 0,7649 & Não \\
\hline 5 & Siderurgia & 1,0806 & 1,5616 & Sim \\
\hline 6 & Máq. e Equip. & 1,1116 & 0,7031 & Não \\
\hline 7 & Mat. Eletroelet. & 1,0992 & 0,8353 & Não \\
\hline 8 & Veíc. e Peças & 1,2324 & 0,8423 & Não \\
\hline 9 & Mad. e Mobil. & 1,0282 & 0,6995 & Não \\
\hline 10 & Celul.. Papel e Gráf. & 1,0453 & 0,9936 & Não \\
\hline 11 & Ind. Borracha & 1,1054 & 0,6201 & Não \\
\hline 12 & Elem. Químicos & 1,146 & 1,2565 & Sim \\
\hline 13 & Ref. Petróleo & 1,244 & 2,034 & Sim \\
\hline 14 & Farmac. / Veter. & 1,0359 & 0,5954 & Não \\
\hline 15 & Art. Plásticos & 1,1557 & 0,817 & Não \\
\hline 16 & Ind. Têxtil & 1,0461 & 0,9578 & Não \\
\hline 17 & Art. Vestuário & 1,0184 & 0,5528 & Não \\
\hline 18 & Fab. Calçados & 1,1766 & 0,6673 & Não \\
\hline 19 & Ind. Alimentos & 1,2871 & 0,9661 & Não \\
\hline 20 & Ind. Diversas & 1,0481 & 0,5762 & Não \\
\hline 21 & S.I.U.P. & 0,9199 & 1,354 & Não \\
\hline 22 & Const. Civil & 0,9469 & 0,6651 & Não \\
\hline 23 & Comércio & 0,7663 & 1,8182 & Não \\
\hline 24 & Transportes & 0,9621 & 1,5247 & Não \\
\hline 25 & Comunicações & 0,9066 & 1,2608 & Não \\
\hline 26 & Inst. Financeiras & 0,8169 & 1,4103 & Não \\
\hline 27 & Serv. Prest. Família & 0,9065 & 0,7185 & Não \\
\hline 28 & Serv. Prest. Empresa & 0,8407 & 1,4398 & Não \\
\hline 29 & Aluguel de Imóveis & 0,5973 & 0,7493 & Não \\
\hline 30 & Adm. Pública & 0,7986 & 0,6147 & Não \\
\hline 31 & Serv. Priv. Não Merc. & 0,847 & 0,6078 & Não \\
\hline
\end{tabular}

Fonte: Elaboração dos autores

É possível observar que os setores que apresentaram os maiores PBLN foram: Administração Pública, Indústria de Alimentos e Serviços Prestados às Famílias, isto é, são os mais demandantes. Estes três setores foram aqueles que causaram maiores impactos na economia, considerando os níveis de produção. Já os setores que apresentaram os maiores PFLN foram: Comércio, Siderurgia e Agropecuária, ou seja, ofertam maiores quantidades de insumos para o restante da economia. Por fim, os setores com maior PTN foram: Indústria de Alimentos, Administração Pública e Comércio. 


\subsection{Multiplicadores}

\subsubsection{Emprego e Renda}

Por meio do coeficiente de emprego e de renda, juntamente com a matriz inversa de Leontief, é possível calcular os multiplicadores de emprego e de renda, mostrando o quanto a economia deve gerar a cada unidade monetária aumentada em determinado setor.

Tabela 3: Multiplicador de Emprego por Nível de Instrução

\begin{tabular}{|c|c|c|c|c|c|c|c|}
\hline \multirow[b]{2}{*}{ Setor } & \multicolumn{7}{|c|}{ Nível de Instrução } \\
\hline & S/ Inst. & $\begin{array}{c}\text { Fund. } \\
\text { Inc. }\end{array}$ & $\begin{array}{l}\text { Fund. } \\
\text { Comp. }\end{array}$ & $\begin{array}{l}\text { Ens. } \\
\text { Méd. } \\
\text { Inc. }\end{array}$ & $\begin{array}{l}\text { Ens. } \\
\text { Méd. } \\
\text { Comp. }\end{array}$ & $\begin{array}{l}\text { Sup. } \\
\text { Inc. }\end{array}$ & $\begin{array}{c}\text { Sup. } \\
\text { Comp. }\end{array}$ \\
\hline Agropecuária & 17,9526 & 39,6799 & 5,5712 & 2,9092 & 6,8372 & 0,6222 & 1,6668 \\
\hline Ext. Mineral & 0,6335 & 2,8683 & 1,3052 & 0,8484 & 4,3402 & 0,7863 & 1,2114 \\
\hline Petróleo e Gás & 0,4431 & 2,5928 & 1,0524 & 0,6943 & 3,1810 & 0,6539 & 1,3761 \\
\hline Min. Não Metál. & 1,5235 & 8,0267 & 2,9761 & 1,8652 & 6,9897 & 1,1088 & 1,8197 \\
\hline Siderurgia & 0,4591 & 2,6235 & 1,3537 & 0,8568 & 4,0657 & 0,7001 & 1,1697 \\
\hline Máq. e Equip. & 0,5051 & 3,1822 & 1,8638 & 1,1466 & 5,6962 & 0,9523 & 1,5370 \\
\hline Mat. Eletroelet. & 0,4994 & 3,1737 & 1,5018 & 1,2520 & 6,4852 & 1,0116 & 1,7297 \\
\hline Veíc. e Peças & 0,5554 & 3,2234 & 1,5618 & 1,1087 & 5,6345 & 0,8987 & 1,6086 \\
\hline Mad. e Mobil. & 3,0030 & 14,5078 & 4,7903 & 2,9649 & 10,0101 & 1,1408 & 1,8398 \\
\hline Celul.. Papel e Gráf. & 1,6543 & 6,0553 & 2,0573 & 1,6224 & 7,0110 & 1,0789 & 2,2694 \\
\hline Ind. Borracha & 1,0843 & 4,4641 & 1,7554 & 1,4206 & 5,2719 & 0,6596 & 1,4116 \\
\hline Elem. Químicos & 2,3791 & 6,2810 & 1,9396 & 1,2309 & 4,8412 & 0,9344 & 1,5925 \\
\hline Ref. Petróleo & 0,5468 & 2,6248 & 1,0125 & 0,7012 & 3,0834 & 0,5762 & 1,1820 \\
\hline Farmac. / Veter. & 1,3290 & 4,7596 & 1,5405 & 1,1885 & 5,1785 & 0,9843 & 1,9991 \\
\hline Art. Plásticos & 0,7669 & 4,3082 & 1,9397 & 1,4270 & 6,5354 & 0,7880 & 1,2616 \\
\hline Ind. Têxtil & 3,3952 & 14,6079 & 5,8553 & 3,2520 & 11,8847 & 1,2656 & 1,8199 \\
\hline Art. Vestuário & 3,5235 & 23,8136 & 10,2765 & 6,0184 & 20,3707 & 1,8827 & 2,7083 \\
\hline Fab. Calçados & 2,1222 & 15,5909 & 6,0446 & 4,3627 & 13,0025 & 1,5109 & 2,0503 \\
\hline Ind. Alimentos & 8,2046 & 21,0375 & 4,1381 & 2,4770 & 7,8635 & 0,9857 & 1,8965 \\
\hline Ind. Diversas & 1,1661 & 7,0399 & 2,7704 & 2,1093 & 10,6292 & 2,2270 & 3,9955 \\
\hline S.I.U.P. & 0,3400 & 1,9673 & 0,9058 & 0,6885 & 2,8244 & 0,5659 & 1,1313 \\
\hline Const. Civil & 3,3302 & 17,5108 & 4,9414 & 2,5188 & 7,4198 & 1,0274 & 1,7364 \\
\hline Comércio & 1,6343 & 9,8763 & 4,6047 & 3,8029 & 15,1559 & 2,1164 & 2,9090 \\
\hline Transportes & 1,0419 & 8,0397 & 3,3674 & 1,9958 & 7,8046 & 1,1051 & 1,9616 \\
\hline Comunicações & 0,4221 & 2,6167 & 1,3372 & 1,1381 & 8,4475 & 2,0850 & 2,9043 \\
\hline Inst. Financeiras & 0,2506 & 1,3305 & 0,6404 & 0,5546 & 3,2388 & 1,2537 & 2,6242 \\
\hline Serv. Prest. Família & 1,8596 & 8,9261 & 3,8890 & 3,3344 & 16,0063 & 4,7863 & 9,7602 \\
\hline Serv. Prest. Empresa & 0,8721 & 5,1804 & 2,5420 & 1,8317 & 10,0984 & 2,7122 & 8,2219 \\
\hline Aluguel de Imóveis & 0,2446 & 1,3945 & 0,5096 & 0,3401 & 1,4973 & 0,3498 & 0,5327 \\
\hline Adm. Pública & 0,8651 & 4,0349 & 1,7202 & 1,3293 & 8,4578 & 2,5086 & 5,1383 \\
\hline Serv. Priv. Não Merc. & 10,4511 & 54,5140 & 14,5419 & 8,3339 & 16,9739 & 0,8403 & 1,7042 \\
\hline
\end{tabular}

Fonte: Elaboração dos autores 
Por meio do coeficiente de emprego e de renda, juntamente com a matriz inversa de Leontief, é possível calcular os multiplicadores de emprego e de renda, mostrando o quanto a economia deve gerar a cada unidade monetária aumentada em determinado setor.

Por meio da Tabela 3 acima, com o acréscimo $\mathrm{R} \$ 1$ milhão nestes setores, a Agropecuária e os Serviços Privados Não Mercantis são aqueles que geram maior quantidade de emprego voltado para as pessoas com baixo nível de instrução (sem instrução e ens. fund. incompleto - grupos um e dois, respectivamente). O setor agropecuário gera 17,9526 e 39,6799 empregos para os grupos um e dois, respectivamente, enquanto que, para os Serviços Privados Não Mercantis, o valor gerado de empregos foi de 10,4511 para o grupo um e 54,5140 para o grupo dois.

Entretanto, estes setores apresentam baixa geração de renda para os níveis mais altos de instrução (ens. sup. incompleto e completo - grupos seis e sete, respectivamente). Neste caso, são os Serviços Prestados à Família e à Empresa que ocupam as maiores posições para estes grupos, gerando 4,7863 empregos para o grupo seis e 9,7602 para o grupo sete para o caso familiar. Já os Serviços Prestados à Empresa geram 2,7122 para o grupo seis e 8,2219 para o grupo sete.

A Tabela 4 apresenta o resultado do multiplicador de renda de cada setor por nível de instrução.

Por meio dos multiplicadores de renda, verifica-se maior retorno na renda quanto maior o nível de instrução do indivíduo. Neste caso, os setores com maiores retornos foram: Administração Pública, Serviços Privados Não Mercantis e Instituições Financeiras.

No entanto, três setores da economia possuem destaque com baixos retornos com relação a estes mesmos grupos (seis e sete): Serviços Prestados às Empresas, Agropecuária e Aluguéis de Imóveis. Com exceção deste último setor, ambos apresentam maiores multiplicadores de renda com baixo nível de instrução. $\mathrm{O}$ setor com menor retorno é o de Aluguel de Imóveis, com baixos multiplicadores em todos os grupos analisados.

Por meio dos multiplicadores de renda, verifica-se maior retorno na renda quanto maior o nível de instrução do indivíduo. Neste caso, os setores com maiores retornos foram: Administração Pública, Serviços Privados Não Mercantis e Instituições Financeiras.

No entanto, três setores da economia possuem destaque com baixos retornos com relação a estes mesmos grupos (seis e sete): Serviços Prestados às Empresas, Agropecuária e Aluguéis de Imóveis. Com exceção deste último setor, ambos apresentam maiores multiplicadores de renda com baixo nível de instrução. O setor com menor retorno é o de Aluguel de Imóveis, com baixos multiplicadores em todos os grupos analisados. 
Tabela 4: Multiplicador de Renda por Nível de Instrução

\begin{tabular}{|c|c|c|c|c|c|c|c|}
\hline \multirow[b]{2}{*}{ Setor } & \multicolumn{7}{|c|}{ Nível de Instrução } \\
\hline & S/ Inst. & $\begin{array}{l}\text { Fund. } \\
\text { Inc. }\end{array}$ & $\begin{array}{l}\text { Fund. } \\
\text { Comp. }\end{array}$ & $\begin{array}{l}\text { Ens. } \\
\text { Méd. } \\
\text { Inc. }\end{array}$ & $\begin{array}{l}\text { Ens. } \\
\text { Méd. } \\
\text { Comp. }\end{array}$ & $\begin{array}{l}\text { Sup. } \\
\text { Inc. }\end{array}$ & $\begin{array}{l}\text { Sup. } \\
\text { Comp. }\end{array}$ \\
\hline Agropecuária & 0,0331 & 0,1230 & 0,0257 & 0,0138 & 0,0538 & 0,0104 & 0,0363 \\
\hline Ext. Mineral & 0,0061 & 0,0343 & 0,0182 & 0,0107 & 0,0781 & 0,0176 & 0,0549 \\
\hline Petróleo e Gás & 0,0066 & 0,0362 & 0,0154 & 0,0431 & 0,0372 & 0,0183 & 0,0831 \\
\hline Min. Não Metál. & 0,0131 & 0,0817 & 0,0357 & 0,0211 & 0,1091 & 0,0242 & 0,0788 \\
\hline Siderurgia & 0,0046 & 0,0359 & 0,0224 & 0,0127 & 0,0772 & 0,0198 & 0,0699 \\
\hline Máq. e Equip. & 0,0057 & 0,0486 & 0,0330 & 0,0176 & 0,1178 & 0,0297 & 0,1061 \\
\hline Mat. Eletroelet. & 0,0046 & 0,0459 & 0,0243 & 0,0176 & 0,1230 & 0,0284 & 0,0863 \\
\hline Veíc. e Peças & 0,0068 & 0,0498 & 0,0298 & 0,0174 & 0,1316 & 0,0274 & 0,0928 \\
\hline Mad. e Mobil. & 0,0127 & 0,0952 & 0,0429 & 0,0226 & 0,1007 & 0,0185 & 0,0553 \\
\hline Celul.. Papel e Gráf. & 0,0079 & 0,0558 & 0,0272 & 0,0186 & 0,1203 & 0,0260 & 0,1033 \\
\hline Ind. Borracha & 0,0087 & 0,0500 & 0,0361 & 0,0283 & 0,1102 & 0,0185 & 0,0821 \\
\hline Elem. Químicos & 0,0104 & 0,0485 & 0,0289 & 0,0179 & 0,0887 & 0,0258 & 0,0721 \\
\hline Ref. Petróleo & 0,0054 & 0,0349 & 0,0155 & 0,0247 & 0,0534 & 0,0167 & 0,0715 \\
\hline Farmac. / Veter. & 0,0087 & 0,0546 & 0,0227 & 0,0177 & 0,1012 & 0,0278 & 0,1082 \\
\hline Art. Plásticos & 0,0083 & 0,0747 & 0,0399 & 0,0281 & 0,1083 & 0,0204 & 0,0631 \\
\hline Ind. Têxtil & 0,0079 & 0,0503 & 0,0241 & 0,0149 & 0,1035 & 0,0279 & 0,1106 \\
\hline Art. Vestuário & 0,0074 & 0,0634 & 0,0341 & 0,0240 & 0,1596 & 0,0246 & 0,0748 \\
\hline Fab. Calçados & 0,0087 & 0,1261 & 0,0590 & 0,0384 & 0,1347 & 0,0363 & 0,0689 \\
\hline Ind. Alimentos & 0,0206 & 0,1007 & 0,0334 & 0,0194 & 0,0926 & 0,0182 & 0,0669 \\
\hline Ind. Diversas & 0,0071 & 0,0638 & 0,0353 & 0,0196 & 0,1019 & 0,0196 & 0,0634 \\
\hline S.I.U.P. & 0,0055 & 0,0408 & 0,0224 & 0,0165 & 0,0758 & 0,0184 & 0,0545 \\
\hline Const. Civil & 0,0164 & 0,1077 & 0,0372 & 0,0180 & 0,0753 & 0,0172 & 0,0559 \\
\hline Comércio & 0,0096 & 0,0770 & 0,0416 & 0,0275 & 0,1464 & 0,0294 & 0,0710 \\
\hline Transportes & 0,0093 & 0,0972 & 0,0459 & 0,0247 & 0,1094 & 0,0195 & 0,0640 \\
\hline Comunicações & 0,0059 & 0,0413 & 0,0187 & 0,0139 & 0,1206 & 0,0400 & 0,0913 \\
\hline Inst. Financeiras & 0,0036 & 0,0247 & 0,0119 & 0,0097 & 0,0768 & 0,0476 & 0,2044 \\
\hline Serv. Prest. Família & 0,0076 & 0,0506 & 0,0231 & 0,0165 & 0,1075 & 0,0398 & 0,1785 \\
\hline Serv. Prest. Empresa & 0,0330 & 0,2017 & 0,0624 & 0,0302 & 0,0924 & 0,0114 & 0,0358 \\
\hline Aluguel de Imóveis & 0,0017 & 0,0121 & 0,0047 & 0,0027 & 0,0174 & 0,0057 & 0,0140 \\
\hline Adm. Pública & 0,0085 & 0,0534 & 0,0276 & 0,0197 & 0,1852 & 0,0734 & 0,3298 \\
\hline Serv. Priv. Não Merc. & 0,0106 & 0,0713 & 0,0380 & 0,0222 & 0,1597 & 0,0516 & 0,3590 \\
\hline
\end{tabular}

\subsubsection{Gênero e Raça}

Após obter os coeficientes de gênero e raça, é possível calcular os multiplicadores destas duas variáveis, que representam a quantidade de emprego gerada a cada $\mathrm{R} \$ 1$ milhão investido nos setores da economia separados por gênero e cor. Os multiplicadores estão representados na Tabela 5 abaixo: 
Tabela 5: Multiplicador de Emprego por Gênero

\begin{tabular}{|c|c|c|}
\hline \multirow{2}{*}{ Setor } & \multicolumn{2}{|c|}{ Gênero } \\
\hline & Masculino & Feminino \\
\hline Agropecuária & 64,8525 & 10,3865 \\
\hline Ext. Mineral & 9,1896 & 2,8036 \\
\hline Petróleo e Gás & 6,7189 & 3,2747 \\
\hline Min. Não Metál. & 18,5558 & 5,7539 \\
\hline Siderurgia & 8,1793 & 3,0492 \\
\hline Máq. e Equip. & 11,068 & 3,8152 \\
\hline Mat. Eletroelet. & 10,4051 & 5,2484 \\
\hline Veíc. e Peças & 10,2336 & 4,3574 \\
\hline Mad. e Mobil. & 27,7691 & 10,4876 \\
\hline Celul.. Papel e Gráf. & 15,5151 & 6,2335 \\
\hline Ind. Borracha & 11,9511 & 4,1164 \\
\hline Elem. Químicos & 14,6287 & 4,57 \\
\hline Ref. Petróleo & 6,5886 & 3,1381 \\
\hline Farmac. / Veter. & 11,8042 & 5,1752 \\
\hline Art. Plásticos & 11,5392 & 5,4877 \\
\hline Ind. Têxtil & 20,125 & 21,9557 \\
\hline Art. Vestuário & 18,0697 & 50,5241 \\
\hline Fab. Calçados & 24,9464 & 19,7377 \\
\hline Ind. Alimentos & 36,6544 & 9,9486 \\
\hline Ind. Diversas & 22,1429 & 7,7946 \\
\hline S.I.U.P. & 4,6213 & 3,802 \\
\hline Const. Civil & 34,5701 & 3,9147 \\
\hline Comércio & 24,6371 & 15,4623 \\
\hline Transportes & 20,4697 & 4,8464 \\
\hline Comunicações & 11,7503 & 7,2006 \\
\hline Inst. Financeiras & 5,6013 & 4,2914 \\
\hline Serv. Prest. Família & 18,9097 & 29,6522 \\
\hline Serv. Prest. Empresa & 19,6221 & 11,8366 \\
\hline Aluguel de Imóveis & 3,5079 & 1,3607 \\
\hline Adm. Pública & 14,9725 & 9,0817 \\
\hline Serv. Priv. Não Merc. & 12,5125 & 94,8468 \\
\hline
\end{tabular}

Fonte: Elaboração dos autores

Com a Tabela 5, observa-se que os três setores que geram maior quantidade de empregos para o sexo masculino são: Agropecuária, Indústria de Alimentos e Construção Civil. É possível verificar também que a quantidade gerada aos homens é bastante superior ao das mulheres, com as seguintes distribuições: Agropecuária (homens: 64,8525 e mulheres: 10,3865), Indústria de Alimentos (homens: 36,6544 e mulheres: 9,9486) e Construção Civil (homens: 34,5701 e mulheres: 3,9147).

Por sua vez, os setores que geram mais empregos para as mulheres são: Serviços Privados Não Mercantis, Artigos do Vestuário e Serviços Prestados 
à Família. Assim como no caso da predominância da mão-de-obra masculina, estes três setores são aqueles com maiores diferenças na quantidade de emprego gerada entre homens e mulheres, sendo: Serviços Privados Não Mercantis (homens: 12,5125 e mulheres: 94,8468), Artigos do Vestuário (homens: 18,0697 e mulheres: 50,5241) e Serviços Prestados à Família (homens: 18,9097 e mulheres: 29,6522).

Analisando o multiplicador por cor, verifica-se que os Serviços Privados Não Mercantis geram maiores quantidades de emprego para todas as raças, com 64,9982 aos não brancos e 42,3611 aos brancos. A Tabela 6 mostra estes multiplicadores:

\begin{tabular}{|c|c|c|}
\hline \multicolumn{3}{|c|}{ Tabela 6: Multiplicador de Emprego por Cor } \\
\hline \multirow{2}{*}{ Setor } & \multicolumn{2}{|c|}{ Cor } \\
\hline & Não Branco & Branco \\
\hline Agropecuária & 46,0096 & 29,2293 \\
\hline Ext. Mineral & 6,2929 & 5,7003 \\
\hline Petróleo e Gás & 4,7524 & 5,2413 \\
\hline Min. Não Metál. & 12,0571 & 12,2526 \\
\hline Siderurgia & 5,0439 & 6,1847 \\
\hline Máq. e Equip. & 6,3967 & 8,4865 \\
\hline Mat. Eletroelet. & 6,7489 & 8,9045 \\
\hline Veíc. e Peças & 6,5225 & 8,0684 \\
\hline Mad. e Mobil. & 18,9684 & 19,2884 \\
\hline Celul.. Papel e Gráf. & 10,3137 & 11,4349 \\
\hline Ind. Borracha & 7,9548 & 8,1127 \\
\hline Elem. Químicos & 9,8308 & 9,3679 \\
\hline Ref. Petróleo & 4,6235 & 5,1032 \\
\hline Farmac. / Veter. & 8,1009 & 8,8785 \\
\hline Art. Plásticos & 7,606 & 9,4208 \\
\hline Ind. Têxtil & 21,0547 & 21,0259 \\
\hline Art. Vestuário & 31,7855 & 36,8083 \\
\hline Fab. Calçados & 19,3167 & 25,3674 \\
\hline Ind. Alimentos & 26,0932 & 20,5097 \\
\hline Ind. Diversas & 13,9416 & 15,9959 \\
\hline S.I.U.P. & 4,0099 & 4,4134 \\
\hline Const. Civil & 22,1557 & 16,3291 \\
\hline Comércio & 18,6662 & 21,4332 \\
\hline Transportes & 12,0905 & 13,2257 \\
\hline Comunicações & 8,2337 & 10,7172 \\
\hline Inst. Financeiras & 3,784 & 6,1088 \\
\hline Serv. Prest. Família & 22,7279 & 25,834 \\
\hline Serv. Prest. Empresa & 13,1931 & 18,2657 \\
\hline Aluguel de Imóveis & 2,2456 & 2,6231 \\
\hline Adm. Pública & 11,3129 & 12,7412 \\
\hline Serv. Priv. Não Merc. & 64,9982 & 42,3611 \\
\hline
\end{tabular}

Fonte: Elaboraçãa dos autores 
Juntamente a este setor citado, os outros dois setores com maiores multiplicadores para ambas as raças são: Artigos de Vestuário (não brancos: 31,7855 e brancos: 36,8083) e Agropecuária (não brancos: 46,0096 e brancos: 29,2293). A diferença existente no multiplicador entre as cores no setor agropecuário se deve, provavelmente, ao fato das pessoas de cor branca possuir maior acesso à educação, atuando em outros setores de maior remuneração. Desta forma, os indivíduos de cor não branca, por não ter as mesmas condições de acesso que os brancos, tendem a atuar em setores que não exigem alto nível de instrução, caso da Agropecuária.

\section{Considerações Finais}

Por meio dos resultados obtidos, através dos índices de RasmussenHirschman, foi possível identificar os setores que apresentam maior nível de dependência em termos de demanda ou de oferta. O setor é considerado chave na economia quando atua fortemente nas áreas de compra e de venda. Dos 31 setores analisados, 25 deles causam grandes impactos pelo lado da demanda ou da oferta, porém, apenas três deles são considerados chaves: Siderurgia, Elementos Químicos e Refino do Petróleo.

No entanto, como estes índices não levam em consideração o nível de produção, é preciso calcular os índices puros de ligação e normalizá-los para analisar comparativamente. Ao fazê-lo, os setores mais demandantes (maior PBLN) foram: Administração Pública, Indústria de Alimentos e Serviços Prestados às Famílias. Já os maiores ofertantes de insumos para os demais setores (maior PFLN) foram: Comércio, Siderurgia e Agropecuária. E por fim, os setores de maior PTN foram: Indústria de Alimentos, Administração Pública e Comércio.

Para verificar a quantidade de emprego e de renda gerada em determinado setor da economia quando ocorre o investimento em $\mathrm{R} \$ 1$ milhão em cada um deles, calculam-se os multiplicadores de emprego e renda. De modo geral, quanto maior o nível educacional do indivíduo, maior a renda gerada. Alguns setores se destacam com maiores multiplicadores, casos da Administração Pública e dos Serviços Privados Não Mercantis, ambos acima de 0,3. Para as pessoas sem instrução, é baixo o retorno, em que nenhum setor apresenta multiplicador próximo de 0,2, com exceção dos Serviços Prestados às Empresas.

Já com relação ao multiplicador de emprego, verifica-se a quantidade gerada com o acréscimo de $\mathrm{R} \$ 1$ milhão em cada setor de acordo com o nível educacional, de gênero e de raça. Com este acréscimo, os setores da Agropecuária e dos Serviços Privados Não Mercantis geram maior quantidade de emprego para os grupos de menor nível de instrução, enquanto que os Serviços Prestados às Famílias e às Empresas são aqueles que geram maior quantidade de emprego para as pessoas mais instruídas.

Considerando os empregos gerados na economia para os sexos feminino 
e masculino, observa-se maior quantidade para elas nos Serviços Privados Não Mercantis e Artigos do Vestuário e, para os homens, os setores com maior número voltado a este público são o Agropecuário e a Indústria de Alimentos. Com relação aos empregos gerados para a raça branca e não branca, os três setores que apresentaram maiores multiplicadores foram os mesmos para ambos os grupos: Serviços Privados Não Mercantis, Artigos de Vestuário e Agropecuária. O destaque vai para o setor Agropecuário, com maior diferença nos multiplicadores entre cores. Conforme já citado, a provável justificativa é o maior acesso à educação por parte do branco.

Com relação aos setores-chaves da economia, os setores de Refino do Petróleo e de Siderurgia apresentam alto multiplicador de emprego para aqueles com ensino médio completo. No caso dos Elementos Químicos, apesar de não possuir o multiplicador mais elevado para este mesmo grupo, devem-se levar em consideração os empregos gerados quando ocorre o investimento neste setor. Cabe destacar também que os multiplicadores de renda destes três setores são os maiores para este grupo, indicando maior rendimento quando aumenta o nível de instrução.

É importante ressaltar que os setores com maior concentração de trabalhadores são aqueles que apresentambaixorendimento médio(Agropecuária e Serviços Prestados Não Mercantis, respectivamente), empregando baixa qualificação da mão-de-obra, isto é, menor nível de instrução. Assim, verificouse, por meio da análise do modelo de insumo-produto, que a educação influencia na renda média da população ocupada positivamente, ocorrendo aumento salarial através da elevação educacional do indivíduo e que as pessoas de cor branca possuem maior nível de instrução e recebem salários mais elevados, indicando um viés de discriminação salarial por raça e gênero no mercado de trabalho brasileiro. 


\section{Referências Bibliográficas}

Almeida R.J.G.; Barros, R.(1991). Wage inequality and the distribution of education: a study of the evolution of the regional differences in inequality in metropolitan Brazil. Journal of Development Economics, n. 36, 1991.

Barros, R. P.; Carvalho, M.(2002). "Políticas ativas de emprego e renda". Mercado de Trabalho: Conjuntura e Análise (IPEA), v. 7, n. 20, p. 61-71, 2002.

Barros, R. P. De; Mendonça, R.(1994). Por que o Brasil é mais pobre do que os países industrializados? In: Araujo, A. B. de. O Brasil no Fim do Século: Desafios e Propostas para a Ação Governamental. Rio de Janeiro: IPEA, p.157-160. 1994.

Barros, R. P. De; Ramos, L.; Santos, E.(1995). Gender Differences in Brazilian Labor Market. In: Schultz, P. Investments in Women's Human Capital. Chicago University Press.

Barros, R. P.; Mendonça, R. S. P.(1995). Os determinantes da desigualdade no Brasil. Brasília: IPEA, 1995.

Barros, R.; Camargo, J.M.; Mendonça, R.(1998). A estrutura do desemprego no Brasil, In: A Economia Brasileira em Perspectiva. Brasília: IPEA, 1998.

Barros, R.; Henriques, R.; Mendonça, R.(2002). Pelos fins da década perdida: Educação e Desenvolvimento Sustentável no Brasil. Rio de Janeiro: IPEA, 2002.

Blair, P. D.; Miller, R. E.(2009). Input-Output Analysis: Foundations and Extensions. 2 Ed. New York: Cambridge University Press.

Bruschini, C.(2007). Trabalho e Gênero no Brasil nos Últimos Dez Anos. Caderno de Pesquisas. v 37, n. 132, set/dez. 2007.

Camargo, J. M.; Serrano, F. L. P.(1983). Os Dois Mercados: Homens e Mulheres na Indústria Brasileira. Rio de Janeiro: Pontifícia Universidade Católica/ Departamento de Economia, (Texto para Discussão, 46).

Cavalieri, C.; Fernandes, R.(1998). Diferenciais de salários por gênero e cor: uma comparação entre as regiões metropolitanas brasileiras. Revista de Economia Política, v. 18, n. 1, 1998.

Fishlow, A.(1972). Brazilian Size Distribution of Income. American Economic Review Proceedings, v. 62, p. 391-402, May 1972.

Guilhoto, J. J. M.(2004). "The regional (state level) importance of the agribusiness GDP in the Brazilian economy“. In Anais do XXXII Encontro Nacional de Economia, João Pessoa-PB.

IBGE (2008). Pesquisa Nacional por Amostra de Domicílios. Rio de Janeiro. Disponível em http://www.ibge.gov.br/home/estatistica/populacao/ trabalhoerendimento/pnad2008/microdados.shtm, 2008.

Kassouf, A. L.(1998). Wage Gender Discrimination and Segmentation in the Brazilian Labor Market. Revista de Economia Aplicada, v. 2, 1998.

Lam, D.; Levinson, D.(1990). Idade, Experiência e Diferenciais de Renda: Estados Unidos e Brasil. Pesquisa e Planejamento Econômico, Rio de Janeiro, v. 20, n. 2, 1990. 
Langoni, C. G.(1973). Distribuição da Renda e Desenvolvimento Econômico do Brasil. Rio de Janeiro, Ed. Expressão e Cultura, 1973.

Leme, C.; Wajnman, S.(2000). Tendências de Coorte nos Diferenciais de Rendimento por Sexo. In: Henriques, R. M. (org.). Desigualdade e Pobreza no Brasil. Rio de Janeiro: IPEA, 2000.

Leontief, W.(1983). A Economia do Insumo-Produto. São Paulo: Abril Cultural, 1983.

Miller, R.(2009). And P. Blair. Input-output analysis: foundations and extensions. Cambridge University Press.

Mincer, J. B.(1974). Schooling, experience and earnings. New York: NBER, 1974. $152 \mathrm{p}$.

Ometto, A. M. H.; Hoffmann, R.; Alves, M. C.(1999). Participação da Mulher no Mercado de Trabalho: Discriminação em Pernambuco e São Paulo. Revista Brasileira de Economia. Rio de Janeiro.

Saboia, A.L; Saboia, J.(2006). 2nd International Conference of the Affirmative Action Studies Network. Rio de Janeiro.

Santos, M.(2010) Ap. Dos. Importância Econômica do Setor Educação no Paraná em 2006: Uma Análise de Insumo-Produto. 2010. 85 f. Dissertação (Mestrado) Universidade Estadual de Londrina, Londrina.

Schultz, T. W.(1960). Capital Formation by Education. The Journal of Political Economy. v. 68, 1960.

Silva, A. M. B.(2008). Matriz de Insumo-Produto: Análise dos Impactos da Educação na Geração de Emprego e Renda na Economia Baiana - 2005. 2008. 196 f. Dissertação (Mestrado) - Universidade Federal da Bahia, Salvador.

Soares, S. S. D.(2000). O Perfil da Discriminação no Mercado de Trabalho (Homens Negros, Mulheres Brancas e Mulheres Negras). Brasília: IPEA, 2000.

Soares, S.; Izaki, R. S.(2002). A Participação Feminina no Mercado de Trabalho. Rio de Janeiro: IPEA, 2002. 
